Network Working Group

Request for Comments: 1799

Category: Informational
M. Kennedy

ISI

January 1997

\title{
Request for Comments Summary
}

RFC Numbers 1700-1799

Status of This Memo

This RFC is a slightly annotated list of the 100 RFCs from RFC 1700 through RFCs 1799. This is a status report on these RFCs. This memo provides information for the Internet community. It does not specify an Internet standard of any kind. Distribution of this memo is unlimited.

Note

Many RFCs, but not all, are Proposed Standards, Draft Standards, or Standards. Since the status of these RFCs may change during the standards processing, we note here only that they are on the standards track. Please see the latest edition of "Internet Official Protocol standards" for the current state and status of these RFCs. In the following, RFCs on the standards track are marked [STANDARDSTRACK].

$\begin{array}{llll}\text { RFC } & \text { Author } & \text { Date } & \text { Title } \\ --- & ----- & --- & \\ & & & \\ 1799 & \text { Kennedy } & \text { Jan } 97 & \text { Requests For Comments Summary }\end{array}$

This memo.

1798 Young Jun 95 Connection-less Lightweight X.500 Directory Access Protocol

The protocol described in this document is designed to provide access to the Directory while not incurring the resource requirements of the Directory Access Protocol (DAP). [STANDARDS-TRACK] 
1797 IANA Apr 95 Class A Subnet Experiment

There appears to be some interest in experimenting with subnetting the class $A$ addresses. It is suggested that conducting an experiment now to identify and fix any software that does not properly handle subnetted class A addresses would be useful and important. This document defines an Experimental Protocol for the Internet community. This does not specify an Internet standard of any kind.

1796 Huitema Apr 95 Not All RFCs are Standards

This document discusses the relationship of the Request for Comments (RFCs) notes to Internet Standards. This memo provides information for the Internet community. This memo does not specify an Internet standard of any kind.

1795 Wells Apr 95

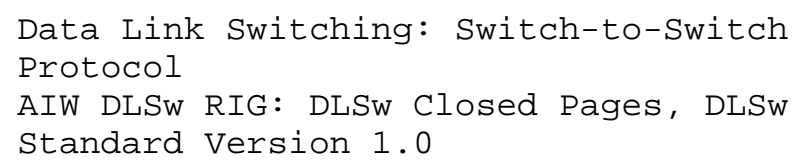

This RFC describes use of Data Link Switching over TCP/IP. This memo provides information for the Internet community. This memo does not specify an Internet standard of any kind.

1794 Brisco Apr 95 DNS Support for Load Balancing

This RFC is meant to first chronicle a foray into the IETF DNS Working Group, discuss other possible alternatives to provide/simulate load balancing support for DNS, and to provide an ultimate, flexible solution for providing DNS support for balancing loads of many types. This memo provides information for the Internet community. This memo does not specify an Internet standard of any kind.

1793 Moy Apr 95 Extending OSPF to Support Demand Circuits

This memo defines enhancements to the OSPF protocol that allow efficient operation over "demand circuits". [STANDARDS-TRACK] 
New MIB objects, tcpIpxConnTable, udpIpxTable, tcpunspecConnTable and udpUnspectable are presented in this paper, to be used in place of tcpConnTable and udpListenerTable when TCP and UDP are running over IPX. This document defines an Experimental Protocol for the Internet community. This does not specify an Internet standard of any kind.

$$
\text { Sung Apr } 95
$$

TCP And UDP Over IPX Networks With Fixed Path MTU

TCP/IPX allows TCP/IP applications to run over IPX networks by letting TCP and UDP run over IPX. And this memo specifies the packet format and operational procedures for running TCP and UDP over IPX. This document defines an Experimental Protocol for the Internet community. This does not specify an Internet standard of any kind.

$1790 \quad$ Cerf Apr 95

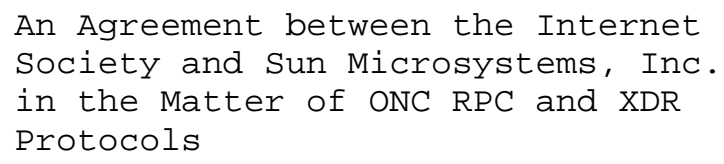

This RFC is an official public record of an agreement between SUN Microsystems and the Internet Society. This memo provides information for the Internet community. It does not specify an Internet standard of any kind.

1789 Yang Apr $95 \quad \begin{aligned} & \text { INETPhone: Telephone Services and } \\ & \text { Servers on Internet }\end{aligned}$

This RFC presents a true telephone service, called INETPhone, which supports voice communication through the Internet. This memo provides information for the Internet community. It does not specify an Internet standard of any kind.

1788 Simpson Apr 95 ICMP Domain Name Messages

This document specifies ICMP messages for learning the Fully Qualified Domain Name associated with an IP address. This document defines an Experimental Protocol for the Internet community. This does not specify an Internet standard of any kind. 
1787 Rekhter Apr 95 Routing in a Multi-provider Internet

This document presents some of the issues related to network layer routing in a multi-provider Internet, and specifically to the unicast routing. This memo provides information for the Internet community. This memo does not specify an Internet standard of any kind.

1786 Bates Mar 95 Representation of IP Routing Policies

This document is an update to the original 'ripe-81' proposal for representing and storing routing polices within the RIPE database. It incorporates several extensions proposed by Merit Inc. and gives details of a generalized IP routing policy representation to be used by all Internet routing registries. It acts as both tutorial and provides details of database objects and attributes that use and make up a routing registry. This memo provides information for the Internet community. This memo does not specify an Internet standard of any kind.

1785 Malkin Mar 95 TFTP Option Negotiation Analysis

This document was written to allay concerns that the presence of options in a TFTP Request packet might cause pathological behavior on servers which do not support TFTP option negotiation. This memo provides information for the Internet community. This memo does not specify an Internet standard of any kind.

1784 Malkin Mar 95 TFTP Timeout Interval and Transfer Size Options

This document describes two TFTP options. The first allows the client and server to negotiate the Timeout Interval. The second allows the side receiving the file to determine the ultimate size of the transfer before it begins. [STANDARDS-TRACK]

1783 Malkin Mar 95 TFTP Blocksize Option

This document describes a TFTP option which allows the client and server to negotiate a blocksize more applicable to the network medium. [STANDARDS-TRACK] 


\section{Malkin Mar 95 TFTP Option Extension}

The Trivial File Transfer Protocol is a simple, lock-step, file transfer protocol which allows a client to get or put a file onto a remote host. This document describes a simple extension to TFTP to allow option negotiation prior to the file transfer.

1781 Kille Mar 95 Using the OSI Directory to Achieve User Friendly Naming

This proposal sets out some conventions for representing names in a friendly manner, and shows how this can be used to achieve really friendly naming. [STANDARDS-TRACK]

1780 IAB Mar 95 Internet Official Protocol Standards

This memo describes the state of standardization of protocols used in the Internet as determined by the Internet Architecture Board (IAB). [STANDARDS-TRACK]

$1779 \quad$ Kille $\quad$ Mar 95

A String Representation of Distinguished Names

The OSI Directory uses distinguished names as the primary keys to entries in the directory. Distinguished Names are encoded in ASN.1. When a distinguished name is communicated between to users not using a directory protocol (e.g., in a mail message), there is a need to have a user-oriented string representation of distinguished name. This specification defines a string format for representing names, which is designed to give a clean representation of commonly used names, whilst being able to represent any distinguished name. [STANDARDS-TRACK]

1778 Howes Mar 95 The String Representation of Standard Attribute Syntaxes

The Lightweight Directory Access Protocol (LDAP) requires that the contents of Attributevalue fields in protocol elements be octet strings. This document defines the requirements that must be satisfied by encoding rules used to render X.500 Directory attribute syntaxes into a form suitable for use in the LDAP, then goes on to define the encoding rules for the standard set of attribute syntaxes. [STANDARDS-TRACK] 
1777 Yeong Mar 95 Lightweight Directory Access Protocol

The protocol described in this document is designed to provide access to the X.500 Directory while not incurring the resource requirements of the Directory Access Protocol (DAP). This protocol is specifically targeted at simple management applications and browser applications that provide simple read/write interactive access to the X.500 Directory, and is intended to be a complement to the DAP itself. [STANDARDS-TRACK]

\begin{abstract}
1776 Crocker Apr 95 The Address is the Message
Declaring that the address is the message, the IPng WG has selected a packet format which includes 1696 bytes of address space. This memo provides information for the Internet community. This memo does not specify an Internet standard of any kind.
\end{abstract}

1775 Crocker Mar 95 To Be "On" the Internet

The Internet permits different levels of access for consumers and providers of service. The nature of those differences is quite important in the capabilities They afford. Hence, it is appropriate to provide terminology that distinguishes among the range, so that the Internet community can gain some clarity when distinguishing whether a user (or an organization) is "on" the Internet. This document suggests four terms, for distinguishing the major classes of access. This memo provides information for the Internet community. This memo does not specify an Internet standard of any kind.

1774 Traina Mar 95 BGP-4 Protocol Analysis

The purpose of this report is to document how the requirements for advancing a routing protocol to Draft Standard have been satisfied by the Border Gateway Protocol version 4 (BGP-4). This report summarizes the key features of BGP, and analyzes the protocol with respect to scaling and performance. This memo provides information for the Internet community. This memo does not specify an Internet standard of any kind. 
1773 Traina Mar 95 Experience with the BGP-4 protocol

The purpose of this memo is to document how the requirements for advancing a routing protocol to Draft standard have been satisfied by Border Gateway Protocol version 4 (BGP-4). This report documents experience with BGP. This memo provides information for the Internet community. This memo does not specify an Internet standard of any kind.

1772 Rekhter Mar 95 Application of the Border Gateway

Protocol in the Internet

This document, together with its companion document, "A Border Gateway Protocol 4 (BGP-4)", define an inter-autonomous system routing protocol for the Internet. This document describes the usage of the BGP in the Internet. [STANDARDS-TRACK]

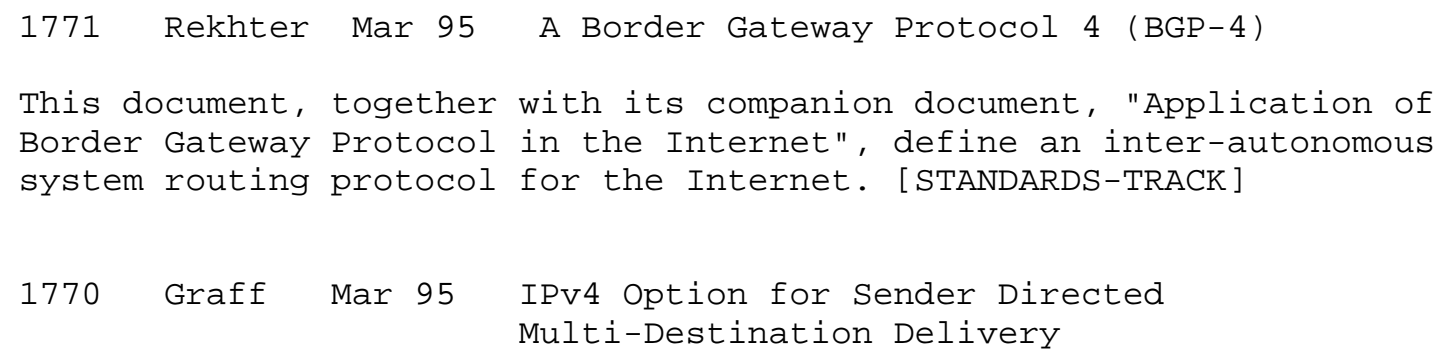

This memo defines an IPv4 option to provide a sender directed multidestination delivery mechanism called Selective Directed Broadcast Mode (SDBM). This memo provides information for the Internet community. This memo does not specify an Internet standard of any kind.

\section{Mils Mar 95 Simple Network Time Protocol (SNTP)}

This memorandum describes the Simple Network Time Protocol (SNTP), which is an adaptation of the Network Time Protocol (NTP) used to synchronize computer clocks in the Internet. This memo provides information for the Internet community. This memo does not specify an Internet standard of any kind. 
1768 Marlow Mar 95 Host Group Extensions for CLNP Multicasting

This memo provides a specification for multicast extensions to the CLNP protocol similar to those provided to IP by RFC1112. This memo defines an Experimental Protocol for the Internet community. This memo does not specify an Internet standard of any kind.

\section{Crocker Mar 95 MIME Encapsulation of EDI Objects}

Since there are many different EDI specifications, the current document defines three distinct categories as three different MIME content-types. [STANDARDS-TRACK]

1766 Alvestrand Mar 95 Tags for the Identification of Languages

This document describes a language tag for use in cases where it is desired to indicate the language used in an information object. [STANDARDS-TRACK]

1765 Moy Mar 95 OSPF Database Overflow

This memo details a way of gracefully handling unanticipated database overflows. This memo defines an Experimental Protocol for the Internet community. This memo does not specify an Internet standard of any kind.

1764 Senum Mar 95 The PPP XNS IDP Control Protocol (XNSCP)

This document defines the Network Control Protocol for establishing and configuring the Xerox Network Systems (XNS) Internet Datagram Protocol (IDP) over PPP. [STANDARDS-TRACK]

1763 Senum Mar 95 The PPP Banyan Vines Control Protocol (BVCP)

This document defines the Network Control Protocol for establishing and configuring the Banyan VINES protocol over PPP. [STANDARDS-TRACK] 
1762 Senum Mar 95 The PPP DECnet Phase IV Control Protocol (DNCP)

This document defines the NCP for establishing and configuring Digital's DNA Phase IV Routing protocol (DECnet Phase IV) over PPP. This document applies only to DNA Phase IV Routing messages (both data and control), and not to other DNA Phase IV protocols (MOP, LAT, etc). [STANDARDSTRACK ]

1761 Callaghan Feb 95 Snoop Version 2 Packet Capture File Format

This paper describes the file format used by "snoop", a packet monitoring and capture program developed by Sun. This paper is provided so that people can write compatible programs to generate and interpret snoop packet capture files. This memo provides information for the Internet community. This memo does not specify an Internet standard of any kind.

1760 Haller Feb 95 The S/KEY One-Time Password System

This document describes the S/KEY* One-Time Password system as released for public use by Bellcore. This memo provides information for the Internet community. This memo does not specify an Internet standard of any kind.

1759 Smith Mar 95 Printer MIB

A printer is the physical device that takes media from an input source, produces marks on that media according to some page description or page control language and puts the result in some output destination, possibly with finishing applied. The information needed in the management of the physical printer and the management of a printing job overlap highly and many of the tasks in each management area require the same or similar information. [STANDARDS-TRACK]

1758 N.A.D.F. Feb 95 NADF Standing Documents: A Brief Overview

The purpose of this document is to provide a brief overview of the NADF's Standing Document series. This memo provides information for the Internet community. This memo does not specify an Internet standard of any kind. 
1757 Waldbusser Feb 95 Remote Network Monitoring Management Information Base

This memo defines a portion of the Management Information Base (MIB) for use with network management protocols in TCP/IP-based internets. In particular, it defines objects for managing remote network monitoring devices. [STANDARDS-TRACK]

1756 Rinne Jan 95 REMOTE WRITE PROTOCOL - VERSION 1.0

This document describes a simple Remote Write Protocol (RWP). This memo defines an Experimental Protocol for the Internet community. This memo does not specify an Internet standard of any kind.

1755 Perez Feb 95 ATM Signaling Support for IP over ATM

This memo describes the ATM call control signaling exchanges needed to support Classical IP over ATM implementations as described in RFC 1577 . [STANDARDS-TRACK]

1754 Laubach Jan 95 IP over ATM Working Group's Recommendations for the ATM Forum's Multiprotocol BOF

Version 1

This document represents an initial list of requirements submitted to the ATM Forum's Multiprotocol BOF for the operation of IP over ATM networks as determined by the IETF IP over ATM Working Group and other working groups. This memo provides information for the Internet community. This memo does not specify an Internet standard of any kind.

1753 Chiappa Dec 94 IPng Technical Requirements of the Nimrod Routing and Addressing Architecture

This document presents the requirements that the Nimrod routing and addressing architecture has upon the internetwork layer protocol. To be most useful to Nimrod, any protocol selected as the IPng should satisfy these requirements. This memo provides information for the Internet community. This memo does not specify an Internet standard of any kind. 
1752 Bradner Jan 95 The Recommendation for the IP Next Generation Protocol

This document presents the recommendation of the IPng Area Directors on what should be used to replace the current version of the Internet Protocol. [STANDARDS-TRACK]

1751 McDonald Dec 94 A Convention for Human-Readable 128-bit Keys

This memo proposes a convention for use with Internet applications \& protocols using 128-bit cryptographic keys. This memo provides information for the Internet community. This memo does not specify an Internet standard of any kind.

1750 Eastlake Dec 94 Randomness Recommendations for Security

Choosing random quantities to foil a resourceful and motivated adversary is surprisingly difficult. This paper points out many pitfalls in using traditional pseudo-random number generation techniques for choosing such quantities. It recommends the use of truly random hardware techniques and shows that the existing hardware on many systems can be used for this purpose. This memo provides information for the Internet community. This memo does not specify an Internet standard of any kind.

1749 McCloghrie Dec 94 IEEE 802.5 Station Source Routing MIB using SMIv2

This memo defines a portion of the Management Information Base (MIB) for use with network management protocols in the Internet community. In particular, it describes managed objects used by IEEE 802.5 end-stations for managing source routes on a Token Ring network where IEEE sourcerouting is in use. [STANDARDS-TRACK]

1748 McCloghrie Dec 94 IEEE 802.5 MIB using SMIv2

This memo defines a portion of the Management Information Base (MIB) for use with network management protocols in the Internet community. In particular, it describes managed objects used for managing subnetworks which use the IEEE 802.5 Token Ring technology described in 802.5 Token Ring Access Method and Physical Layer Specifications, IEEE Standard 802.5-1989. [STANDARDS-TRACK] 
1747 Hilgeman Jan 95 Definitions of Managed Objects for SNA Data Link Control (SDLC) using SMIv2

This specification defines an extension to the Management Information Base (MIB) for use with SNMP-based network management. In particular, it defines objects for managing the configuration, monitoring and control of data link controls in an SNA environment. [STANDARDS-TRACK]

1746 Manning Dec 94 Ways to Define User Expectations

This paper covers basic fundamentals that must be understood when one defines, interprets, or implements methods to control user expectations on or over the Internet. This memo provides information for the Internet community. This memo does not specify an Internet standard of any kind.

1745 Varadhan Dec 94 BGP4/IDRP for IP---OSPF Interaction

This memo defines the various criteria to be used when designing an Autonomous system Border Router (ASBR) that will run either BGP 4 or IDRP for IP with other ASBRs external to the AS and OSPF as its IGP. [STANDARDS-TRACK]

1744 Huston Dec 94 Observations on the Management of the Internet Address Space

This memo examines some of the issues associated with the current management practices of the Internet IPV4 address space, and examines the potential outcomes of these practices as the unallocated address pool shrinks in size. This memo provides information for the Internet community. This memo does not specify an Internet standard of any kind.

1743 McCloghrie Dec 94 IEEE 802.5 MIB using SMIv2

This memo defines a portion of the Management Information Base (MIB) for use with network management protocols in the Internet community. In particular, it describes managed objects used for managing subnetworks which use the IEEE 802.5 Token Ring technology described in 802.5 Token Ring Access Method and Physical Layer Specifications, IEEE Standard 802.5-1989. [STANDARDS-TRACK] 
This memo defines a portion of the Management Information Base (MIB) for use with network management protocols in TCP/IP-based internets. In particular, it defines objects for managing AppleTalk networks. [STANDARDS-TRACK]

Falstrom

Dec 94 MIME Content Type for BinHex Encoded Files

This memo describes the format to use when sending BinHex4.0 files via MIME [BORE93]. This memo provides information for the Internet community. This memo does not specify an Internet standard of any kind.

$$
\text { Falstron Dec } 94
$$

MIME Encapsulation of Macintosh Files MaCMIME

This memo describes the format to use when sending Apple Macintosh files via MIME [BORE93]. [STANDARDS-TRACK]

1739 Kessler Dec 94 A Primer On Internet and TCP/IP Tools

This memo is an introductory guide to some of the TCP/IP and Internet tools and utilities that allow users to access the wide variety of information on the network, from determining if a particular host is up to viewing a multimedia thesis on foreign policy. It also describes discussion lists accessible from the Internet, ways to obtain Internet documents, and resources that help users weave their way through the Internet. This memo provides information for the Internet community. This memo does not specify an Internet standard of any kind.

1738 Berners-Lee Dec 94 Uniform Resource Locators (URL)

This document specifies a Uniform Resource Locator (URL), the syntax and semantics of formalized information for location and access of resources via the Internet. [STANDARDS-TRACK]

1737 Sollins Dec 94 Functional Requirements for Uniform Resource Names

This document specifies a minimum set of requirements for a kind of Internet resource identifier known as Uniform Resource Names (URNs). This memo provides information for the Internet community. This memo does not specify an Internet standard of any kind. 
1736 Kunze Feb 95 Functional Recommendations for Internet Resource Locators

This document specifies a minimum set of requirements for Internet resource locators, which convey location and access information for resources. This memo provides information for the Internet community. This memo does not specify an Internet standard of any kind.

1735 Heinanen Dec 94 NBMA Address Resolution Protocol (NARP)

This document describes the NBMA Address Resolution Protocol (NARP). NARP can be used by a source terminal (host or router) connected to a Non-Broadcast, Multi-Access link layer (NBMA) network to find out the NBMA addresses of the a destination terminal provided that the destination terminal is connected to the same NBMA network. This memo defines an Experimental Protocol for the Internet community. This memo does not specify an Internet standard of any kind.

1734 Myers Dec 94 POP3 AUTHentication command

This document describes the optional AUTH command, for indicating an authentication mechanism to the server, performing an authentication protocol exchange, and optionally negotiating a protection mechanism for subsequent protocol interactions. [STANDARDS-TRACK]

1733 Crispin Dec 94 Distributed Electronic Mail

Models in IMAP 4

There are three fundamental models of client/server email: offline, online, and disconnected use. IMAP4 can be used in any one of these three models. This memo provides information for the Internet community. This memo does not specify an Internet standard of any kind.

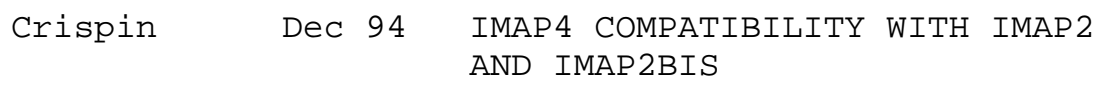

This is a summary of hints and recommendations to enable an IMAP4 implementation to interoperate with implementations that conform to earlier specifications. This memo provides information for the Internet community. This memo does not specify an Internet standard of any kind. 
1731 Myers Dec 94 IMAP4 Authentication Mechanisms

The Internet Message Access Protocol, Version 4 [IMAP4] contains the AUTHENTICATE command, for identifying and authenticating a user to an IMAP4 server and for optionally negotiating a protection mechanism for subsequent protocol interactions. This document describes several authentication mechanisms for use by the IMAP4 AUTHENTICATE command. [STANDARDS-TRACK]

1730 Crispin Dec 94 Internet Message Access Protocol

- Version 4

The Internet Message Access Protocol, Version 4 (IMAP4) allows a client to access and manipulate electronic mail messages on a server. IMAP4 permits manipulation of remote message folders, called "mailboxes", in a way that is functionally equivalent to local mailboxes. IMAP4 also provides the capability for an offline client to resynchronize with the server. [STANDARDS-TRACK]

1729 Lynch Dec 94 Using the z39.50 Information

Retrieval Protocol in the Internet

Environment

This memo describes an approach to the implementation of the ANSI/NISO Z39.50-1992 Standard for Information Retrieval in the TCP/IP environment which is currently in wide use by the 739.50 implementor community. This memo provides information for the Internet community. This memo does not specify an Internet standard of any kind.

1728 Weider Dec 94 Resource Transponders

This paper describes an automatic mechanism, the resource transponder, for maintaining resource location information. This memo provides information for the Internet community. This memo does not specify an Internet standard of any kind.

1727 Weider Dec 94 A Vision of an Integrated Internet Information Service

This paper lays out a vision of how Internet information services might be integrated over the next few years, and discusses in some detail what steps will be needed to achieve this integration. This memo provides information for the Internet community. This memo does not specify an Internet standard of any kind. 
1726 Partridge Dec 94 Technical Criteria for Choosing IP The Next Generation (IPng)

This RFC specifies criteria related to mobility for consideration in design and selection of the Next Generation of IP. This memo provides information for the Internet community. This memo does not specify an Internet standard of any kind.

1725 Myers Nov 94 Post Office Protocol - Version 3

This memo is a revision to RFC 1460, a Draft Standard. [STANDARDS-TRACK]

1724 Malkin Nov 94 RIP Version 2 MIB Extension

This memo defines a portion of the Management Information Base (MIB) for use with network management protocols in TCP/IP-based internets. In particular, it defines objects for managing RIP Version 2. [STANDARDSTRACK ]

1723 Malkin Nov $94 \quad$ RIP Version 2

Carrying Additional Information

This document specifies an extension of the Routing Information Protocol (RIP), o expand the amount of useful information carried in RIP messages and to add a measure of security. This memo obsoletes RFC 1388, which specifies an update to the "Routing Information Protocol" STD 34, RFC 1058. [STANDARDS-TRACK]

1722 Malkin Nov 94 RIP Version 2 Protocol Applicability Statement

As required by Routing Protocol Criteria (RFC 1264), this report defines the applicability of the RIP-2 protocol within the Internet. This report is a prerequisite to advancing RIP-2 on the standards track. [STANDARDS-TRACK] 
1721 Malkin Nov 94 RIP Version 2 Protocol Analysis

As required by Routing Protocol Criteria (RFC 1264), this report documents the key features of the RIP-2 protocol and the current implementation experience. This report is a prerequisite to advancing RIP-2 on the standards track. This memo provides information for the Internet community. This memo does not specify an Internet standard of any kind.

1720 IAB Nov 94 Internet Official Protocol Standards

This memo describes the state of standardization of protocols used in the Internet as determined by the Internet Architecture Board (IAB). [STANDARDS-TRACK]

1719 Gross Dec 94 A Direction for IPng Specification and Implementation

This RFC specifies criteria related to mobility for consideration in design and selection of the Next Generation of IP. This memo provides information for the Internet community. This memo does not specify an Internet standard of any kind.

1718 IETF Secretariat Nov 94 The Tao of IETF

A Guide for New Attendees of the Internet Engineering Task Force

The purpose of this For Your Information (FYI) RFC is to explain to the newcomers how the IETF works. This memo provides information for the Internet community. It does not specify an Internet standard. [FYI 17]

1717 Sklower Nov 94 The PPP Multilink Protocol (MP)

This document proposes a method for splitting, recombining and sequencing datagrams across multiple logical data links. [STANDARDSTRACK ] 
1716 Almquist Nov $94 \quad$ Towards Requirements for IP Routers

The goal of this work is to replace RFC-1009, Requirements for Internet Gateways ([INTRO:1]) with a new document. It defines and discusses requirements for devices which perform the network layer forwarding function of the Internet protocol suite. This memo provides information for the Internet community. This memo does not specify an Internet standard of any kind.

1715 Huitema Nov 94 The H Ratio for Address Assignment Efficiency

This document was submitted to the IETF IPng area in response to RFC 1550. This memo provides information for the Internet community. This memo does not specify an Internet standard of any kind.

1714 Williamson Nov 94 Referral Whois Protocol (RWhois)

This memo describes version 1.0 of the client/server interaction of RWhois. RWhois provides a distributed system for the display of hierarchical information. This memo provides information for the Internet community. This memo does not specify an Internet standard of any kind.

1713 Romao Nov 94 Tools for DNS debugging

Although widely used (and most of the times unnoticed), DNS (Domain Name System) is too much overlooked, in the sense that people, especially administrators, tend to ignore possible anomalies as long as applications that need name-to-address mapping continue to work. This document presents some tools available for domain administrators to detect and correct those anomalies. This memo provides information for the Internet community. This memo does not specify an Internet standard of any kind.

1712 Farrell Nov 94 DNS Encoding of Geographical Location

This document defines the format of a new Resource Record (RR) for the Domain Naming System (DNS), and reserves a corresponding DNS type mnemonic and numerical code. This memo defines an Experimental Protocol for the Internet community. This memo does not specify an Internet standard of any kind. 
1711 Houttuin Oct 94 Classifications in E-mail Routing

This paper presents a classification for e-mail routing issues. This memo provides information for the Internet community. This memo does not specify an Internet standard of any kind.

1710 Hinden Oct 94 Simple Internet Protocol Plus White Paper

This document was submitted to the IETF IPng area in response to RFC 1550. This memo provides information for the Internet community. This memo does not specify an Internet standard of any kind.

1709 Gargano Nov $94 \quad$ K-12 Internetworking Guidelines

The K-12 community traditionally has not had this level of staffing available for telecommunications planning. This document is intended to bridge that gap and provides a recommended technical direction, an introduction to the role the Internet now plays in $\mathrm{K}-12$ education and technical guidelines for building a campus data communications infrastructure that provides internetworking services and connections to the Internet. This memo provides information for the Internet community. This memo does not specify an Internet standard of any kind.

1708 Gowin Oct 94 NTP PICS PROFORMA

For the Network Time Protocol

Version 3

This RFC describes a PICS Proforma translated into an Internet acceptable form. This memo provides information for the Internet community. This memo does not specify an Internet standard of any kind.

1707 McGovern Oct 94

CATNIP: Common Architecture for the Internet

This document was submitted to the IETF IPng area in response to RFC 1550. This paper describes a common architecture for the network layer protocol. This memo provides information for the Internet community. This memo does not specify an Internet standard of any kind. 
1706 Manning Oct 94 DNS NSAP Resource Records

This document defines the format of one new Resource Record (RR) for the DNS for domain name-to-NSAP mapping. The RR may be used with any NSAP address format. This memo provides information for the Internet community. This memo does not specify an Internet standard of any kind.

1705 Carlson Oct 94 Six Virtual Inches to the Left: The Problem with IPng

This document was submitted to the IETF IPng area in response to RFC 1550. This RFC suggests that a new version of TCP (TCPng), and UDP, be developed and deployed. This memo provides information for the Internet community. This memo does not specify an Internet standard of any kind.

1704 Haller Oct 94 On Internet Authentication

This document describes a spectrum of authentication technologies and provides suggestions to protocol developers on what kinds of authentication might be suitable for some kinds of protocols and applications used in the Internet. This document provides information for the Internet community. This memo does not specify an Internet standard of any kind.

1703 Rose Oct 94

\author{
Principles of Operation for the TPC.INT \\ Subdomain: \\ Radio Paging -- Technical Procedures
}

This memo describes a technique for radio paging using the Internet mail infrastructure. In particular, this memo focuses on the case in which radio pagers are identified via the international telephone network. This memo provides information for the Internet community. This memo does not specify an Internet standard of any kind.

1702 Hanks Oct 94 Generic Routing Encapsulation over IPv4 networks

This memo addresses the case of using IP as the delivery protocol or the payload protocol and the special case of IP as both the delivery and payload. This memo also describes using IP addresses and autonomous system numbers as part of a GRE source route. This memo provides information for the Internet community. This memo does not specify an Internet standard of any kind. 
1701 Hanks Oct 94 Generic Routing Encapsulation (GRE)

This document specifies a protocol for performing encapsulation of an arbitrary network layer protocol over another arbitrary network layer protocol. This memo provides information for the Internet community. This memo does not specify an Internet standard of any kind.

\section{Reynolds Oct $94 \quad$ Assigned Numbers}

This RFC is a snapshot of the ongoing process of the assignment of protocol parameters for the Internet protocol suite. To make the current information readily available the assignments are kept up-todate in a set of online text files. This memo is a status report on the parameters (i.e., numbers and keywords) used in protocols in the Internet community.

Security Considerations

Security issues are not discussed in this memo.

Author's Address

Mary Kennedy

University of Southern California

Information Sciences Institute

4676 Admiralty Way

Marina del Rey, CA 90292

Phone: (310) 822-1511

EMail: MKENNEDYQISI.EDU 